\title{
Deconstruction of the Surgical Approach to the Jugular Foramen Region: Anatomical Study
}

\author{
$\operatorname{Jaafar}$ Basma1,2 L. Madison Michael II ${ }^{1,2,3}$ Jeffrey M. Sorenson ${ }^{1,2,3}$ Jon H. Robertson ${ }^{1,2,3}$ \\ ${ }^{1}$ Department of Neurosurgery, University of Tennessee Health \\ Sciences Center, Memphis, Tennessee, United States \\ 2 Medical Education Research Institute, Memphis, Tennessee, United States \\ ${ }^{3}$ Semmes-Murphey Clinic, Memphis, Tennessee, United States

\begin{abstract}
Address for correspondence Jaafar Basma, MD, Department of Neurosurgery, University of Tennessee Health Sciences Center, 847 Monroe Avenue, Suite 427, Memphis, TN 38163, United States (e-mail: jbasma@uthsc.edu).
\end{abstract}

J Neurol Surg B 2019;80:518-526.

\begin{abstract}
\section{Keywords}

- jugular foramen

- far lateral

- infralabyrinthine approach

- styloid process

- occipital condyle

- cranial nerves

- distal cervical approach

Introduction The jugular foramen occupies a complex and deep location between the skull base and the distal-lateral-cervical region. We propose a morphometric anatomical model to deconstruct its surgical anatomy and offer various quantifiable targetguided exposures and angles-of-attack.

Methods Six cadaveric heads (12 sides) were dissected using a combined postauricular infralabyrinthine and distal transcervical approach with additional anterior transstyloid and posterior far lateral exposures. We identified anatomical landmarks and combined new and previously described contiguous triangles to expose the region; we defined the jugular and deep condylar triangles. Angles-of-attack to the jugular foramen were measured after removing the digastric muscle, styloid process, rectus capitis lateralis, and occipital condyle.

Results Removing the digastric muscle and styloid process allowed $86.4^{\circ}$ laterally and $85.5^{\circ}$ anteriorly, respectively. Resecting the rectus capitis lateralis and jugular process provided the largest angle-of-attack ( $108.4^{\circ}$ posteriorly). The occipital condyle can be drilled in the deep condylar triangle only adding $30.4^{\circ}$ medially. A purely lateral approach provided a total of $280.3^{\circ}$. Cutting the jugular ring and mobilizing the vein can further expand the medial exposure.

Conclusion The microsurgical anatomy of the jugular foramen can be deconstructed using a morphometric model, permitting a surgical approach customized to the pathology of interest.
\end{abstract}

\section{Introduction}

Lesions involving the jugular foramen continue to be challenging surgical targets for the modern neurosurgeon. This is mainly due to their deep location, proximity to major neurovascular structures ( $\mathbf{- F i g . 1}$ ), and potential high vascularity and invasiveness. Anatomical knowledge, coupled with meticulous microsurgical technique, is a key element in planning and executing any surgical intervention in this area.

The relatively benign natural history of many of these lesions, along with advancements in radiation therapy, has reduced the surgical indications in the management of jugular

received

August 6, 2018

accepted after revision

October 25, 2018

published online

December 7, 2018

foramen pathologies. However, the neurosurgeon and headand-neck surgeon should always consider surgery in complex lesions that are not amenable to radiation therapy alone. These include lesions of larger size, with malignant biological behavior, compressing the brain stem, and/or encasing important neurovascular elements resulting in neurological deficits. ${ }^{1}$

A multitude of surgical approaches and procedures has been described to access the jugular foramen, including the following: the preauricular transinfratemporal fossa approach, ${ }^{2}$ distal cervical approaches with mandibular procedures, ${ }^{3-5}$ the lateral transtemporal infralabyrinthine approach, ${ }^{6-8}$ the juxtacondylar

(c) 2019 Georg Thieme Verlag KG Stuttgart · New York
Dol https://doi.org/ 10.1055/s-0038-1676512. ISSN 2193-6331. 


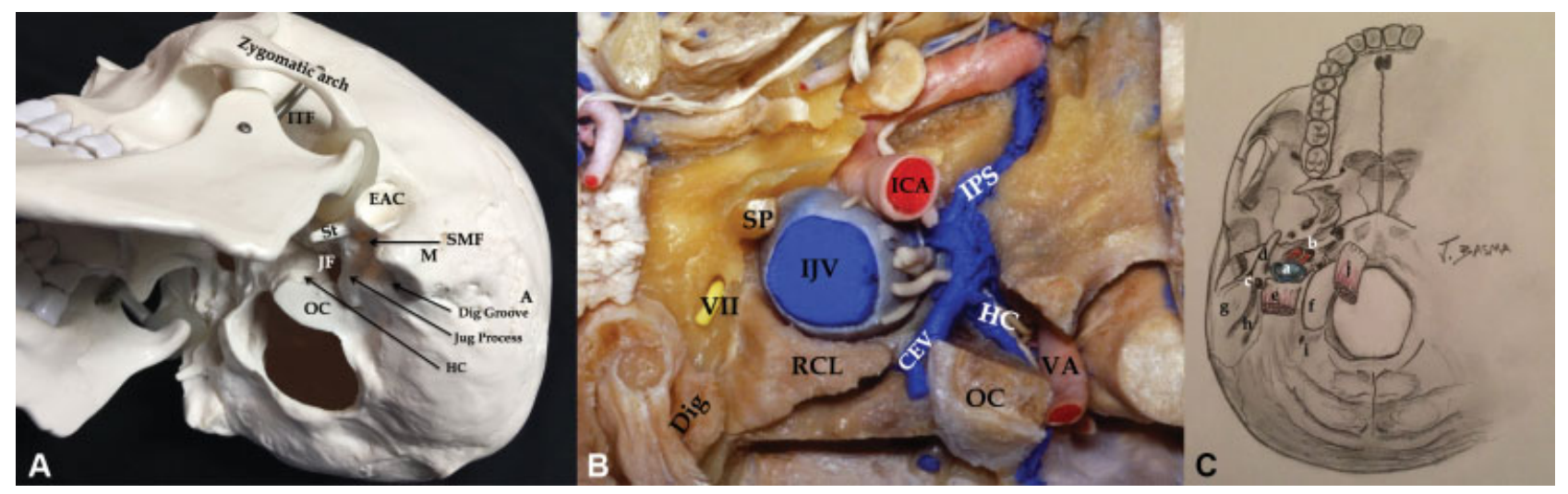

Fig. 1 Anatomy of the jugular foramen. (A) The infratemporal fossa (ITF) represents the anterior aspect of the lateral external skull base, while the jugular foramen (JF) occupies its posterior part. Bony borders of the jugular foramen include the jugular process of the occipital bone posteriorly, mastoid bone (M) and digastric groove laterally, styloid process (St) anterolaterally, and occipital condyle (OC) medially. Other abbreviations: A, asterion; EAC, external auditory canal; HC, hypoglossal canal; SMF, stylomastoid foramen. (B) Anatomical dissection with an inferior view to the jugular foramen region. The internal carotid artery (ICA) enters the petrous bone anterior to the jugular vein (IJV). The rectus capitis lateralis (RCL) muscle inserts on the jugular process of the occipital bone. (Reprinted from the online Rhoton Collection.) Other abbreviations: CEV, condylar emissary vein; Dig, digastric muscle; IPS, inferior petrosal sinus; SP, styloid process; VA, vertebral artery; VII, facial nerve. (C) Drawing illustrating the limits of the jugular foramen: (a) jugular vein; (b) internal carotid artery; (c) stylomastoid foramen; (d) styloid process; (e) rectus capitis lateralis muscle; (f) occipital condyle; (g) mastoid process; (h) digastric groove; (i) condylar canal; (j) rectus capitis anterior muscle.

approach, ${ }^{9,10}$ the infrajugular transjugular tubercle approach, $^{11,12}$ the retrolabyrinthine and translabyrinthine suprajugular approaches, ${ }^{13}$ the far lateral supracondylar and paracondylar approaches, ${ }^{14,15}$ the extreme lateral approach, ${ }^{16}$ and recently the endoscopic and endonasal approaches. ${ }^{17}$ Although there is a wide variability in the involved steps, several approaches overlap and there is a lack of a standard surgical language to simplify the anatomical understanding and the rationale behind choosing the appropriate surgical approach for individual cases. $^{18}$

Our approach has been to use the lateral distal cervical postauricular approach to access pathologies involving the jugular foramen. ${ }^{19,20}$ This approach offers a straightforward corridor to the region, and its versatility allows for multiple adaptations to specific lesions. Exposure can be obtained without requiring major mandibular procedures, facial nerve rerouting, or condylar and occipitocervical destabilization.

In this article, we quantify the angles-of-attack to the jugular foramen through the posterolateral perspective. Case examples are used to illustrate the anatomical scheme and the rationale involved in customizing the approach to the targeted pathology.

\section{Methods}

Six preserved cadaveric heads (12 sides) were dissected at the Medical Education and Research Institute microsurgical laboratory in Memphis, Tennessee, United States. The heads had no known intracranial or cervical pathology and were fixed and injected with colored silicone rubber. All cadaver specimens had preserved distal necks proximally at least to the level of the omohyoid muscle.

A retroauricular curvilinear C-shaped skin incision was made $3 \mathrm{~cm}$ posterior to the pinna and continued inferiorly to the neck over the anterior border of the sternocleidomastoid muscle. The cutaneous and muscular flaps were dissected separately and reflected anteriorly to fully expose the mastoid triangle, defined between the asterion, mastoid tip, and suprameatal crest. ${ }^{21}$ The neck was dissected using a standard medial sternocleidomastoid approach. We explored the carotid triangle-outlined by the omohyoid, the sternocleidomastoid muscle, and the digastric muscles-to expose the carotid sheath and lower cranial nerves (-Figs. 2 and 3). ${ }^{22}$ The vagus nerve was dissected between the internal jugular vein and the internal carotid artery, and the hypoglossal nerve was identified in its anterior course just below the digastric muscle.

Three major bony structures were palpated as key landmarks to deconstruct the approach: the mastoid tip, styloid process, and transverse process of the atlas (TP-C1). Muscular attachments to these structures defined surgical triangles, which were progressively unlocked (-Fig. 2).

The stylodigastric triangle was defined between the digastric groove, styloid process, and the intersection between the digastric and stylohyoid muscles (-Fig. 3). ${ }^{22}$ Detaching the digastric muscle and mobilizing it inferiorly exposed the TP-C1 and the surrounding deep musculature (i.e., the superior oblique, inferior oblique, and rectus capitis lateralis). The accessory nerve was identified as it crossed the anteroinferior border of TP-C1. We typically identified the accessory nerve in that region before detaching the sternocleidomastoid muscle to avoid its inadvertent injury. The facial nerve was dissected between the styloid and the mastoid processes before it enters the parotid gland. The glossopharyngeal nerve was identified as it courses anteriorly and laterally to the internal carotid artery, just posterior to the stylopharyngeus muscle.

Muscular triangles at the deeper level were recognized after removing the digastric muscle, and carefully dissected. These included the suboccipital triangle (found between the superior and inferior oblique muscles), ${ }^{23}$ and the condylar triangle (found between the superior oblique and rectus 


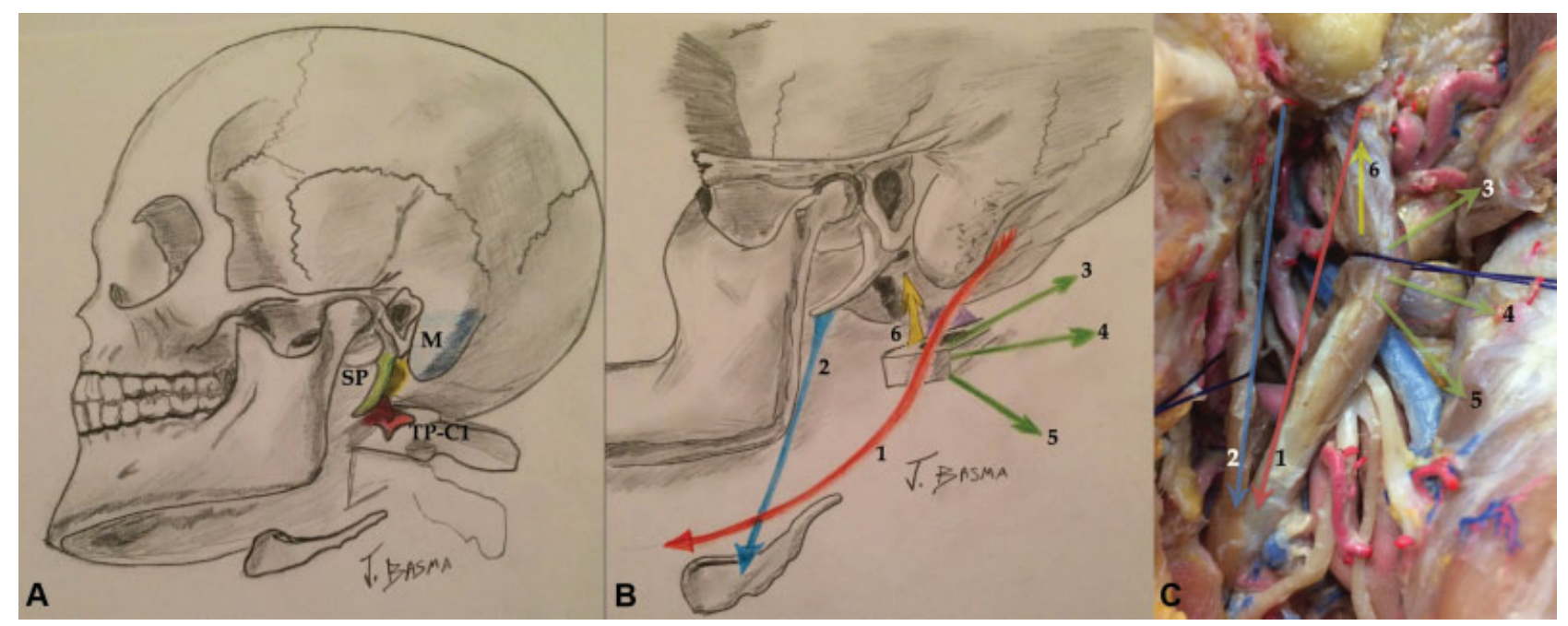

Fig. 2 Surgical landmarks and triangular framework. (A) The mastoid tip (M), styloid process (SP), and transverse process of the atlas (TP-C1) are three major bony structures, which can be palpated to guide the surgical approach to the jugular foramen. (B, C) Several muscles attach to and/or cross these structures, such as the (1) digastric, (2) stylohyoid, (6) rectus capitis lateralis, (3) superior oblique, (4) inferior oblique, and (5) levator scapulae muscles. These muscles delineate well-defined surgical triangles, such as the stylodigastric, suboccipital, and condylar triangles.
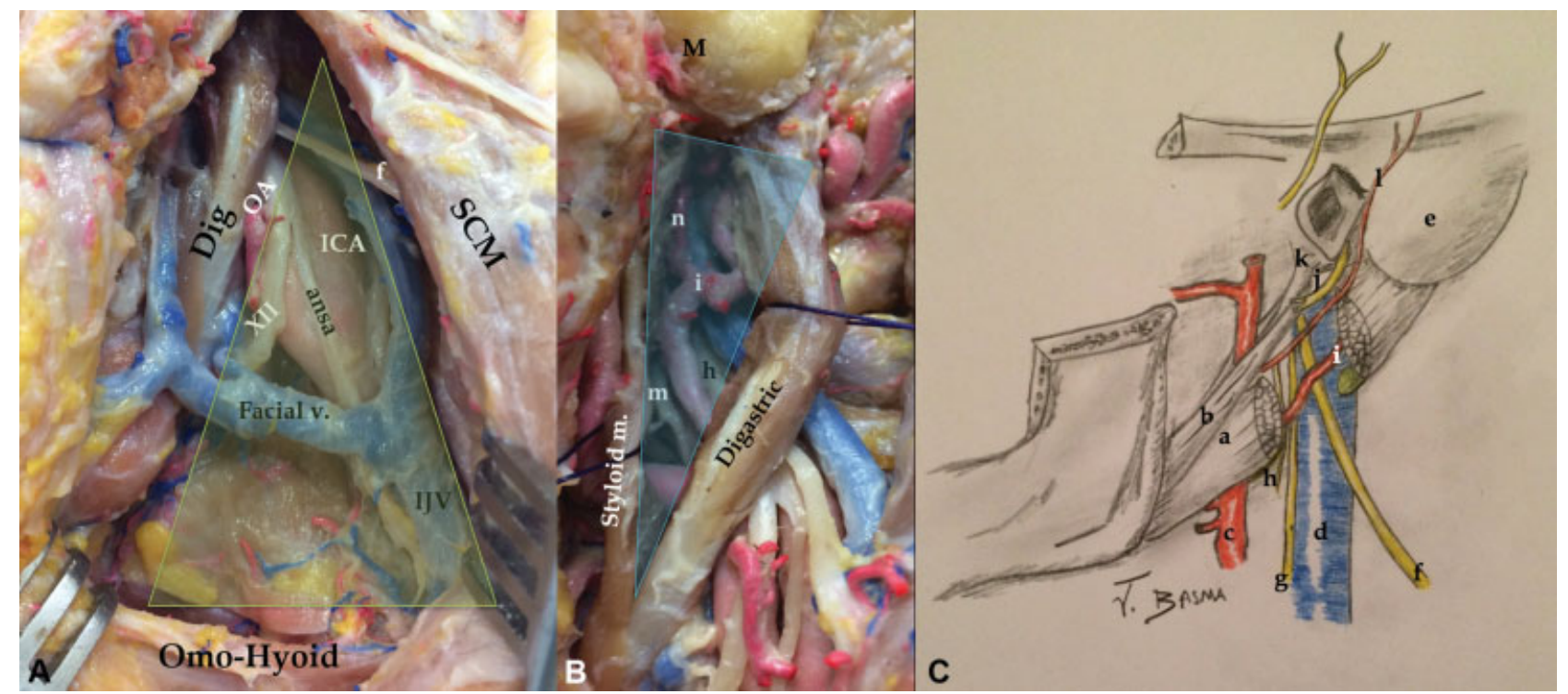

Fig. 3 (A) The carotid triangle is limited by the sternocleidomastoid (SCM), and the digastric (Dig) and omohyoid muscles. It contains the carotid bifurcation and internal carotid artery (ICA), internal jugular vein (IJV) and its branches, the hypoglossal nerve (XII) and ansa cervicalis, the accessory nerve $(\mathrm{XI})$, and the origin of occipital artery (OA). (B, C) The stylodigastric triangle is defined by the (a) digastric muscle, (b) the styloid muscles, and an imaginary line between the digastric groove and base of the styloid process. Labels: (c) external carotid artery; (d) internal jugular vein; (e) mastoid process; ( $f$ ) accessory nerve; $(\mathrm{g}$ ) vagus nerve; (h) hypoglossal nerve; (i) occipital artery; (j) facial nerve; (k) styloid process; (I) posterior auricular artery; (m) glossopharyngeal nerve; (n) artery to the stylomastoid foramen.

capitis lateralis muscles). ${ }^{24}$ We also defined the jugular triangle between rectus capitis lateralis, TP-C1, and the base of the styloid process. This triangle represented the lateral limit of the jugular foramen (-Fig. 4).

After reflecting the superior oblique muscle and to help predict the precise location of the occipital condyle, we established the "deep condylar triangle," defined between the condylar emissary vein, jugular process of the occipital bone (the site of insertion of the rectus capitis lateralis), and TP-C1 (-Fig. 4). Retracting the vertebral artery inferiorly fully exposed the occipital condyle and the atlanto-occipital joint. We then drilled the occipital condyle to unveil the hypoglossal and condylar canals. Removing the bone superior to the hypoglossal canal directed us to the jugular tubercle and defined the suprahypoglossal triangle between the hypoglossal dura inferiorly, foramen magnum dura medially, and jugular bulb laterally. Drilling below the hypoglossal canal exposed the infrahypoglossal triangle between hypoglossal dura, atlanto-occipital joint, and jugular foramen (-Fig. 4). ${ }^{25}$

We drilled the mastoid triangle to complete both an infralabyrinthine and retrolabyrinthine approach, ${ }^{21}$ and 


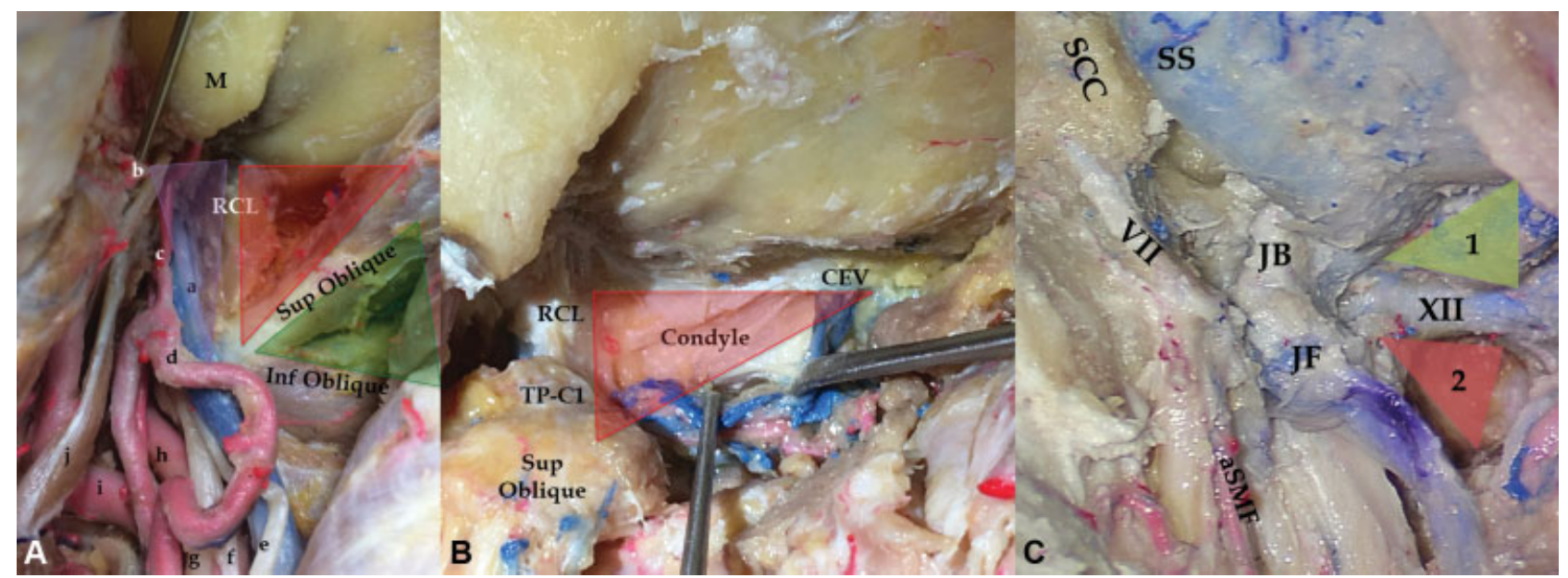

Fig. 4 (A) Detaching the digastric muscle exposes the deeper surgical triangles, including the suboccipital triangle (green), limited by the superior and inferior obliques muscles; the condylar triangle (red), between the superior oblique and the rectus capitis lateralis (RCL); and the jugular triangle (purple), between the RCL, TP-C1, and the base of the styloid. Labels: (a) internal jugular vein; (b) facial nerve; (c) artery of the stylomastoid foramen; (d) occipital artery (reflected down); (e) accessory nerve; (f) vagus nerve; (g) hypoglossal nerve; (h) internal carotid; (i) external carotid; (j) stylohyoid muscle. (B) The deep condylar triangle is exposed after reflecting the superior oblique muscle; the atlanto-occipital joint is seen after retracting the vertebral artery. Abbreviations: CEV, condylar emissary vein; TP-C1, transverse process of the atlas. (C) The (1) suprahypoglossal and (2) infrahypoglossal triangles are shown after drilling the occipital condyle. Abbreviations: aSMF, artery of stylomastoid foramen; JB, jugular bulb; SCC, semicircular canals; SS, sigmoid sinus; VII, facial nerve; XII, hypoglossal nerve.

we skeletonized the fallopian canal. The region of the jugular foramen was identified between the rectus capitis lateralis and the jugular process of the occipital bone posteriorly, the stylomastoid foramen and the facial nerve laterally, and the styloid process anterolaterally. A fibrous structure-the jugular ring-was identified around the jugular vein at that level. Cutting this ring allowed us to mobilize the vein and expose the lower cranial nerves medially. Further medial exposure was limited by the inferior petrosal sinus, which had to be divided to complete the mobilization of the jugular vein at the skull base (-Fig. $\mathbf{5}$ ).

We quantified the angles-of-attack to the jugular foramen, using the jugular vein at the level of the jugular ring as reference. The perimeter of the jugular vein was measured after its complete exposure from which we deduced its radius by approximating its shape into a perfect cylinder ( $r=P / 2 \pi$, where $r$ is the radius of the jugular vein at the skull base and $P$ is its perimeter). Specific surgical steps resulted in the visualization of certain arcs of the jugular vein at the skull base in the axial plane. These arcs were marked with dye, and their length measured with a thread and caliper. We were then able to measure the exposed arc lengths of the jugular vein after performing each of the following steps: (1) drilling the mastoid bone and detaching the digastric muscle, (2) removing the rectus capitis lateralis muscle and drilling the jugular process of the occipital bone, (3) removing the styloid process and styloid muscles, and (4) drilling the occipital condyle. The angles of exposure after each step were deduced mathematically from the formula: $\operatorname{arc}$ (degrees) $=180 . \mathrm{L} / \pi . r$, where $L$ is the exposed arc length and $r$ is the radius of the jugular vein at the jugular foramen.

We then considered the jugular fossa from a craniocaudal perspective. The sigmoid sinus assumed an anterolateral turn toward the jugular bulb above the level of the jugular
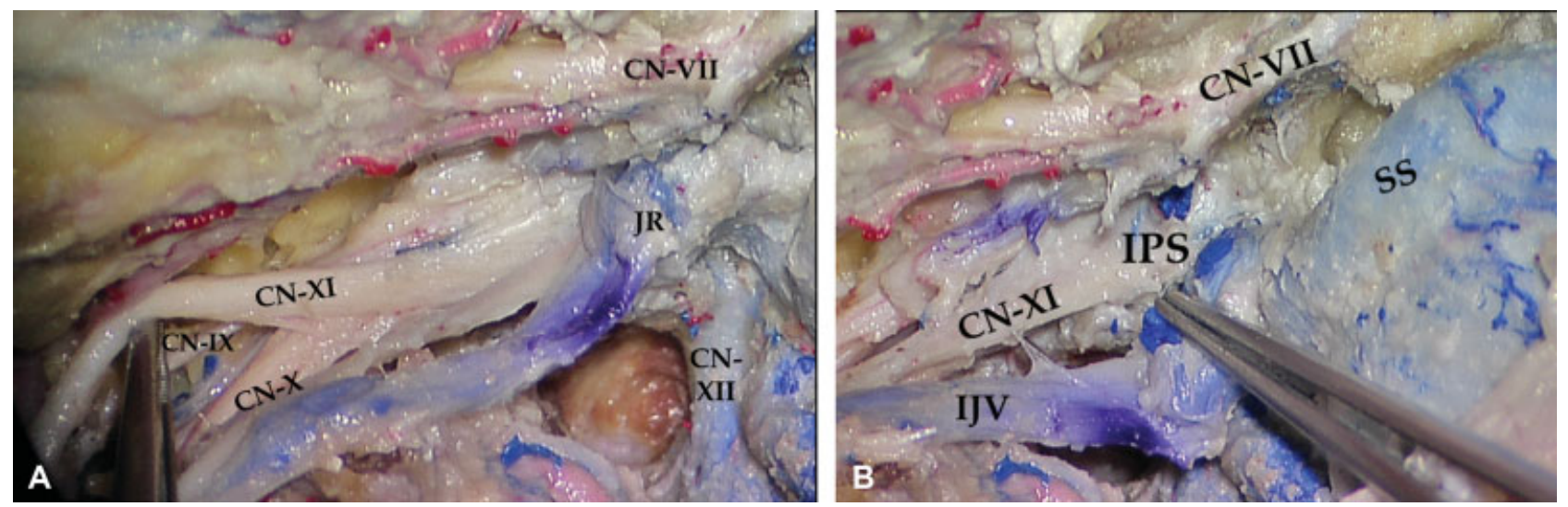

Fig. 5 (A) The jugular vein can be gently mobilized after cutting the jugular ring (JR), exposing the lower cranial nerves medially. (B) Further medial exposure is limited by the inferior petrosal sinus (IPS), a tributary of the jugular vein (IJV) at the jugular foramen. Abbreviations: CN, cranial nerve; SS, sigmoid sinus. 
foramen, separating anatomical spaces above and below the jugular fossa. We qualitatively examined the suprajugular angle-of-attack through the mastoid bone, and the infrajugular angle through the occipital condyle.

Representative cases were chosen to illustrate the advantages of customizing surgical approaches to the jugular foramen.

\section{Results}

\section{Anatomical Boundaries of the Jugular Foramen}

The microsurgical anatomy of the jugular foramen has been previously described in detail. ${ }^{8,26}$ We summarize the anatomical boundaries of the jugular fossa and foramen in - Table 1 . Understanding these limits is necessary to plan the surgical approach and tailor it to the targeted pathology. Briefly, the jugular fossa is limited by the labyrinth superiorly; internal carotid artery anteriorly; styloid process anterolaterally; rectus capitis lateralis, TP- $\mathrm{C} 1$, and the vertebral artery posteriorly; hypoglossal nerve and occipital condyle medially; mastoid bone, digastric muscle, and facial nerve laterally (-Fig. 1). Since the jugular foramen has a deep location at the interface between the distal neck and the external skull base, access to each of its borders requires opening specific surgical corridors.

\section{Surgical Triangles}

Triangles of the distal cervical region and posterolateral skull base have been previously described in separate reports. ${ }^{21-25}$ We deconstructed the jugular foramen anatomy into contiguous triangles, similar to cavernous sinus and middle fossa triangles (-Table 2). These triangles, defined by specific landmarks (the mastoid tip, TP-C1, and styloid process), create a simplified surgical roadmap to the region (-Fig. 2 ).

The carotid triangle gives access to the proximal carotid artery and its bifurcation, internal jugular vein, and lower cranial nerves X, XI, and XII. The glossopharyngeal nerve is identified in the stylodigastric triangle anteriorly and laterally to the distal internal carotid artery (-Fig. 3). Detaching the digastric muscle exposes the distal internal jugular vein as it enters the jugular foramen anteriorly to the rectus capitis lateralis. This muscle and the styloid base define the "jugular triangle," which is the lateral limit of the jugular foramen (-Fig.4). On the other hand, removing the styloid process and its muscles opens the anterior aspect of the stylodigastric triangle, exposing the distal internal carotid artery. Drilling the mastoid bone inferior and posterior to the labyrinth in the mastoid triangle completes the exposure of the sigmoid sinus and the jugular bulb superiorly (suprajugular triangle ${ }^{25}$ ).

The superior and inferior oblique muscles are identified after reflecting the digastric muscle. The vertebral artery can be safely dissected between these muscles in the suboccipital triangle. On the superior side of the superior oblique, we find the condylar triangle, which is bound laterally by the rectus capitis lateralis and harbors the occipital condyle. When present, the condylar emissary vein helps define the medial limit of the occipital condyle in the "deep condylar triangle" (discerned in $80 \%$ of our specimens). If the condylar emissary vein is not present, the lateral border of the foramen magnum can be used as a medial limit to the deep condylar triangle. Drilling the cancellous bone of the occipital condyle exposes the cortical bone of the hypoglossal canal. The area above the hypoglossal canal leads to the jugular tubercle (suprahypoglossal or supracondylar triangle), while below, the infrahypoglossal triangle gives access to the occipitocervical joint (-Fig. 4).

\section{Angles-of-Attack to the Jugular Foramen}

The average length of the jugular vein from the skull base to the lower edge of the digastric muscle was $39.3 \mathrm{~mm}$. After removing the jugular ring and mobilizing the jugular vein at the jugular foramen, its average perimeter was found to be $17.3 \mathrm{~mm}$ (range, $12-24 \mathrm{~mm}$ ). Its calculated radius was $2.75 \mathrm{~mm}$. Drilling the infralabyrinthine mastoid bone and reflecting the digastric muscle exposed an arc length of $4.1 \mathrm{~mm}$ at the lateral aspect of the jugular vein as it enters the skull base. This allowed an average angle-of-attack of

Table 1 Boundaries of the jugular fossa and the jugular foramen ${ }^{a}$

\begin{tabular}{|l|l|l|l|l|}
\hline Border & Bone intracranial & Bone extracranial & Neurovascular structures & Muscle \\
\hline Superior & Otic capsule & $\begin{array}{l}\text { EAC } \\
\text { Tympanic cavity }\end{array}$ & $\begin{array}{l}\text { Cochlea } \\
\text { SCC's }\end{array}$ & Tensor tympani \\
\hline Anterior & $\begin{array}{l}\text { Carotid canal } \\
\text { (vertical segment) }\end{array}$ & $\begin{array}{l}\text { Carotid ridge } \\
\text { Styloid process and } \\
\text { vaginal process of TB }\end{array}$ & Internal carotid artery & $\begin{array}{l}\text { Styloid muscles } \\
\text { Tensor tympani }\end{array}$ \\
\hline Posterior & Sigmoid groove & $\begin{array}{l}\text { Jugular process } \\
\text { of occipital bone } \\
\text { TP of atlas }\end{array}$ & $\begin{array}{l}\text { Vertebral artery } \\
\text { C1 nerve root }\end{array}$ & Rectus capitis lateralis \\
\hline Medial & $\begin{array}{l}\text { Occipital condyle } \\
\text { Jypoglossal canal }\end{array}$ & $\begin{array}{l}\text { Occipital condyle } \\
\text { Hypoglossal canal }\end{array}$ & Hypoglossal nerve & Rectus capitis anterior \\
\hline Lateral & Mastoid air cells & $\begin{array}{l}\text { Mastoid } \\
\text { Digastric groove } \\
\text { Styloid } \\
\text { Mandibular ramus }\end{array}$ & $\begin{array}{l}\text { Facial nerve } \\
\text { Occipital artery }\end{array}$ & $\begin{array}{l}\text { Digastric } \\
\text { SCM } \\
\text { Styloid muscles }\end{array}$ \\
\hline
\end{tabular}

Abbreviations: EAC, external auditory canal; SCC: semicircular canals; SCM, sternocleidomastoid muscle; TB, temporal bone; TP, transverse process. ${ }^{\text {a }}$ Since the jugular foramen is located at the transition between the skull base and the distal neck, each border has an intracranial and an extracranial aspect. 
Table 2 Skull base and distal cervical triangles leading to the region of the jugular foramen ${ }^{\text {a }}$

\begin{tabular}{|c|c|c|c|c|}
\hline \multirow{2}{*}{$\begin{array}{l}\text { Triangle } \\
\text { (1) Carotid }\end{array}$} & \multicolumn{3}{|c|}{ Borders (length in $\mathrm{mm}$ ) } & \multirow{2}{*}{$\begin{array}{l}\text { Contents } \\
\text { CCA, ICA, ECA, IJV, CN X-XII, ansa }\end{array}$} \\
\hline & $\begin{array}{l}\text { SCM } \\
(56.3)\end{array}$ & $\begin{array}{l}\text { Omohyoid } \\
(27)\end{array}$ & $\begin{array}{l}\text { Digastric } \\
(45.6)\end{array}$ & \\
\hline (2) Mastoid & $\begin{array}{l}\text { SMC to } \\
\text { asterion } \\
(26.2)\end{array}$ & $\begin{array}{l}\text { SMC to } \\
\text { mastoid tip } \\
(33.2)\end{array}$ & $\begin{array}{l}\text { Asterion to } \\
\text { mastoid tip } \\
(43.7)\end{array}$ & $\begin{array}{l}\text { Sigmoid sinus, jugular bulb, otic } \\
\text { capsule, CN VII, ES }\end{array}$ \\
\hline (3) Stylodigastric & $\begin{array}{l}\text { Digastric groove } \\
\text { to base of styloid } \\
(27)\end{array}$ & $\begin{array}{l}\text { Styloid muscles } \\
(38.7)\end{array}$ & $\begin{array}{l}\text { Digastric } \\
\text { (posterior belly) } \\
(48.7)\end{array}$ & $\begin{array}{l}\text { CN VII, CN IX, posterior auricular } \\
\text { artery, distal IJV, distal ECA/ICA }\end{array}$ \\
\hline (4) Jugular & $\begin{array}{l}\mathrm{RCL} \\
(20.8)\end{array}$ & $\begin{array}{l}\text { TPC1 to } \\
\text { styloid base } \\
(21.6)\end{array}$ & $\begin{array}{l}\text { Jugular process } \\
\text { to styloid base } \\
(25.4)\end{array}$ & $\begin{array}{l}\text { Lateral jugular foramen and IJV, } \\
\text { CN VII-XII, ICA }\end{array}$ \\
\hline (5) Suboccipital & $\begin{array}{l}\text { Superior oblique } \\
(44.5)\end{array}$ & $\begin{array}{l}\text { Inferior oblique } \\
(37.1)\end{array}$ & $\begin{array}{l}\text { Rectus capitis } \\
\text { posterior } \\
\text { major }(28.1)\end{array}$ & $\begin{array}{l}\text { Vertebral artery, C1 nerve root, } \\
\text { venous plexus }\end{array}$ \\
\hline (6) Condylar & $\begin{array}{l}\text { Superior oblique } \\
(45)\end{array}$ & $\begin{array}{l}\mathrm{RCL} \\
(21.1)\end{array}$ & $\begin{array}{l}\text { Occipital bone } \\
(39.8)\end{array}$ & $\begin{array}{l}\text { Occipital condyle, occipital artery, } \\
\text { hypoglossal canal }\end{array}$ \\
\hline (7) Deep Condylar & $\begin{array}{l}\text { RCL to } C E V^{b} \\
(22.8)\end{array}$ & $\begin{array}{l}\mathrm{CEV}^{\mathrm{b}} \text { to TPC1 } \\
(26.8)\end{array}$ & $\begin{array}{l}\mathrm{RCL} \\
(17.6) \\
\end{array}$ & $\begin{array}{l}\text { Hypoglossal canal } \\
\text { CEV }\end{array}$ \\
\hline (8) Suprahypoglossal & $\begin{array}{l}\text { Hypoglossal dura } \\
(9.8)\end{array}$ & $\begin{array}{l}\text { Suboccipital/foramen } \\
\text { magnum dura } \\
(5.1)\end{array}$ & $\begin{array}{l}\text { Jugular bulb } \\
(6.3)\end{array}$ & Jugular tubercle \\
\hline (9) Infrahypoglossal & $\begin{array}{l}\text { Hypoglossal dura } \\
(10.1)\end{array}$ & $\begin{array}{l}\text { Atlanto-occipital joint } \\
(9.1)\end{array}$ & $\begin{array}{l}\text { Jugular foramen } \\
\text { (5.1) }\end{array}$ & Atlanto-occipital joint \\
\hline
\end{tabular}

Abbreviations: CCA, common carotid artery; CEV, condylar emissary vein; CN, cranial nerve; ECA, external carotid artery; ES, endolymphatic sac; ICA, internal carotid artery; IJV, internal jugular vein; RCL, rectus capitis lateralis; SCM, sternocleidomastoid muscle; SMC, suprameatal crest; TPC1, transverse process of the atlas.

${ }^{\text {a }}$ The length of each triangular border is the average of 12 measurements obtained from the dissected specimens.

${ }^{b}$ If the CEV is not present, the lateral aspect of the foramen magnum was used as a landmark.

$86.4^{\circ}$. Removing the rectus capitis lateralis exposed an additional arc length of $5.2 \mathrm{~mm}$ with a posterior angle of exposure of $108.4^{\circ}$. Detaching the styloid muscle and the styloid process exposed an arc length of $4.1 \mathrm{~mm}$ of the internal jugular vein with an anterior angle-of-attack of $85.5^{\circ}$ (-Fig. 6). It also allowed further access to the distal internal carotid artery as it enters the petrous canal. Combining these three steps, which can be performed through a lateral postauricular distal cervical approach, provided a total of $280.3^{\circ}$ of exposure around the jugular foramen.

Drilling the occipital condyle added an exposed arc length of $1.4 \mathrm{~mm}$ with a medial angle of $30.4^{\circ}$ in the horizontal plane. However, from a craniocaudal perspective, drilling the occipital condyle and the jugular tubercle allowed for an inferior angle-of-attack to the jugular fossa (infrajugular). On the other hand, drilling the retrolabyrinthine mastoid bone increased the exposure superior to the jugular bulb (suprajugular angle-of-attack) ( - Fig.6). The jugular bulb was found to be high riding in five sides (in $42 \%$ of cases). When the jugular bulb is low-lying, there is a larger "supra-jugular" space that can be used to widen the presigmoid exposure.

\section{Discussion}

Deconstructing the anatomy of the jugular foramen into surgical windows helps in understanding the overlap between the different approaches and their variations. Depending on the desired angle-of-attack, individual steps can be selectively added to each approach and adjusted to the tumor location and extension. Among the different approaches, the lateral transtemporal approach offers a $280^{\circ}$ exposure around the jugular foramen region, even without mandibular dislocation or drilling the occipital condyle.

Several mandibular procedures are employed to widen the exposure anteriorly to the jugular foramen and to the distal carotid artery, including mandibulotomy, mandibulectomy, mandibular subluxation, and vertical ramus osteotomy. ${ }^{3-5}$ These may result in higher morbidities, such as malocclusion, temporomandibular joint dysfunction, wound infection, painful clinical recovery, and cranial nerve injury. Removing the styloid process provides adequate exposure to the distal carotid artery and to the anterior aspect of the jugular foramen in many cases ( - Fig. 7). Drilling the vaginal process of the tympanic bone and mobilizing the internal carotid artery can further expand this exposure. However, if the pathology is originating anteriorly in the infratemporal fossa and displacing the carotid artery posteriorly, then it is more appropriate to perform an anterior preauricular subtemporal-infratemporal fossa approach. ${ }^{2,8}$

Being the superior border of the carotid triangle, the digastric represents a natural obstacle to the lateral aspect of the distal carotid artery and internal jugular vein. The 


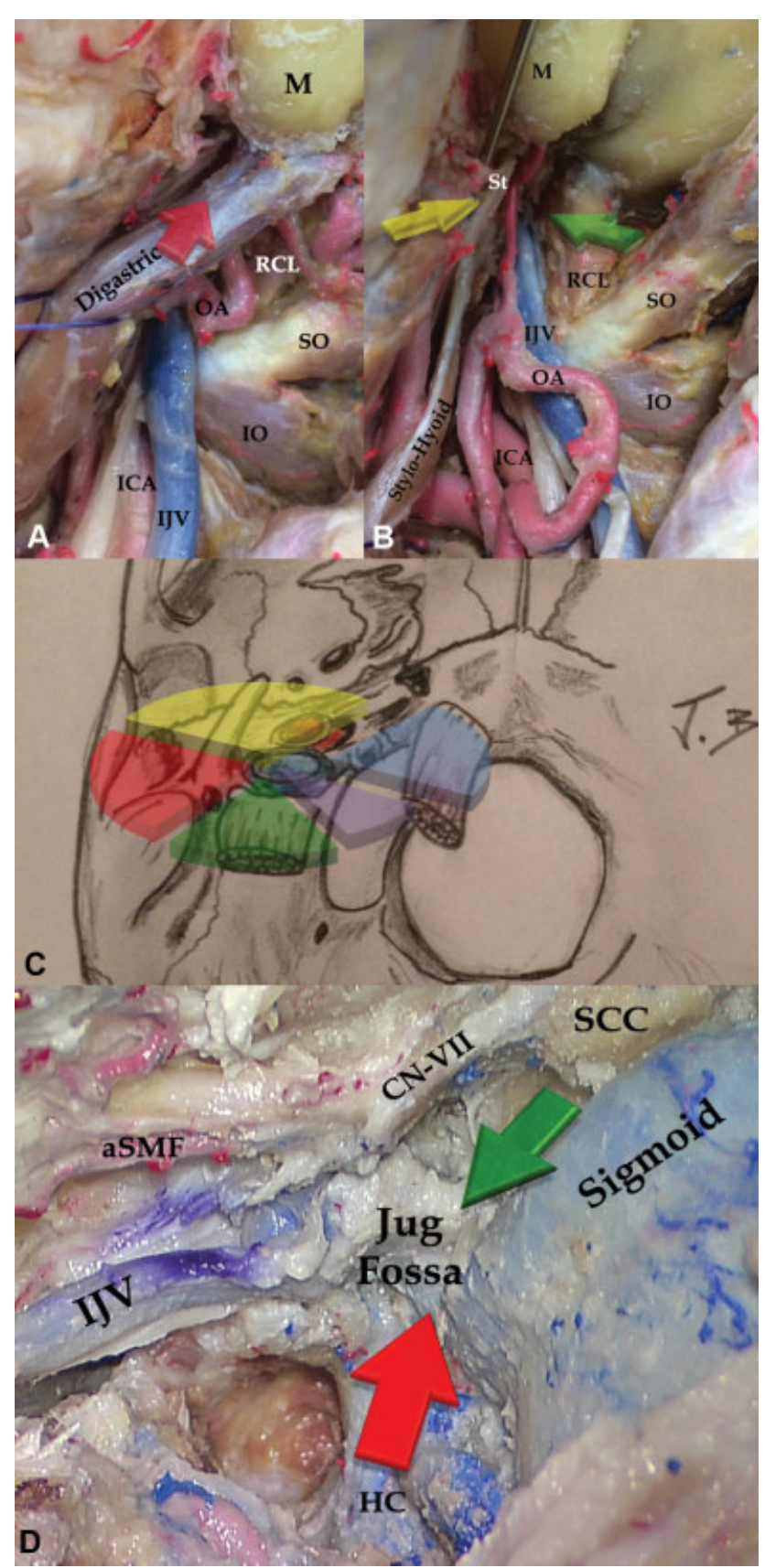

Fig. 6 Angles of attack to the jugular foramen. The digastric muscle allows for a lateral exposure $(A)$, while the styloid process and the rectus capitis lateralis provide access to the anterior and posterior aspects of the jugular foramen, respectively (B). Abbreviations: ICA, internal carotid artery; IJV, internal jugular vein; IO, inferior oblique muscle; $\mathrm{M}$, mastoid process; $\mathrm{OA}$, occipital artery; $\mathrm{RCL}$, rectus capitis lateralis; SO, superior oblique muscle. (C) Measured angles of attack to the jugular foramen depicted in an anatomical drawing. Legend: Red, digastric muscle; green, rectus capitis lateralis; yellow, styloid process; purple, occipital condyle; blue, medial exposure. (D) Transcondylar infrajugular (red arrow) and retrolabyrinthine suprajugular (green arrow) angles of attack to the jugular foramen. Abbreviations: aSMF, artery of the stylomastoid foramen; HC, hypoglossal canal; SCC, semicircular canals.

digastric groove lies at the lateral aspect of the jugular foramen between the mastoid process of the temporal bone and the jugular process of the occipital bone. Detaching the digastric muscle is a key step in exposing the distal internal carotid artery and jugular foramen. ${ }^{27,28}$ Care must be taken to avoid injuring the accessory nerve and occipital artery traversing underneath it. An infralabyrinthine mastoidectomy is also necessary to access the lateral aspect of the sigmoid sinus and jugular foramen superiorly.

Removing the rectus capitis lateralis muscle and drilling the jugular process of the occipital bone have been advocated by the senior author to significantly increase the posterior exposure around the jugular foramen. ${ }^{20}$ This step was found to add the widest angle-of-attack to the jugular foramen in our study. This maneuver can also be performed from a posterior exposure through a paracondylar extension of the far lateral approach. ${ }^{14}$ The rectus capitis lateralis muscle and the condylar triangle it defines with the superior oblique muscle are useful intraoperative landmarks in understanding the overlap between the posterior and lateral approaches. ${ }^{14,24}$

Exposure of the medial aspect of the jugular foramen can be achieved from a lateral approach. If the pathology is intrajugular (e.g., a glomus jugulare tumor), the jugular vein is opened and the medial wall kept intact to protect the lower cranial nerves coursing beneath it. Sometimes the tumor creates a trans-sigmoid/jugular corridor to the jugular foramen, and its tract can be safely followed after securing a proximal and distal venous control. If the pathology is extrajugular, the jugular ring can be cut and the vein mobilized, allowing better visualization of the lower cranial nerves medially (e.g., lower cranial nerve schwannomas). However, the jugular vein is tethered at the skull base by the inferior petrosal sinus and care must be taken to avoid avulsing the vein during such medial dissections.

The far lateral, presigmoid, and retrosigmoid extensions can be added to further address the medial intradural and intracranial aspect of the jugular foramen. The retrosigmoid and presigmoid approaches are particularly indicated for tumors extending intracranially from the jugular foramen, or those extending to the jugular foramen area from an intracranial origin, such as lower cranial nerve dumbbell-shaped schwannomas. The suprajugular bone inferior to the internal auditory meatus and surrounding the glossopharyngeal fold can be drilled intracranially to expose the roof of the jugular foramen and the glossopharyngeal nerve. ${ }^{13}$

Drilling the occipital condyle in our study did not significantly increase the medial exposure to the jugular foramen. However, and especially when the jugular tubercle is resected (i.e., the supracondylar approach), it did allow for an inferior angle-of-attack to the jugular fossa. The supracondylar approach is traditionally directed above the hypoglossal nerve, medially through the jugular tubercle, to increase the exposure to the clivus and basal cisterns. ${ }^{15,16}$ Capitalizing on the infrajugular exposure, a juxtacondylar approach to the jugular foramen has been endorsed, which relies on the resection of the jugular tubercle with a more limited mastoidectomy. This approach permits an inferior access to the jugular foramen compared with the superior and lateral exposure obtained by the infralabyrinthine transtemporal approach. ${ }^{9,10}$ On the other hand, extending the mastoidectomy to include the retrolabyrinthine or translabyrinthine regions provides a wider suprajugular exposure above the 


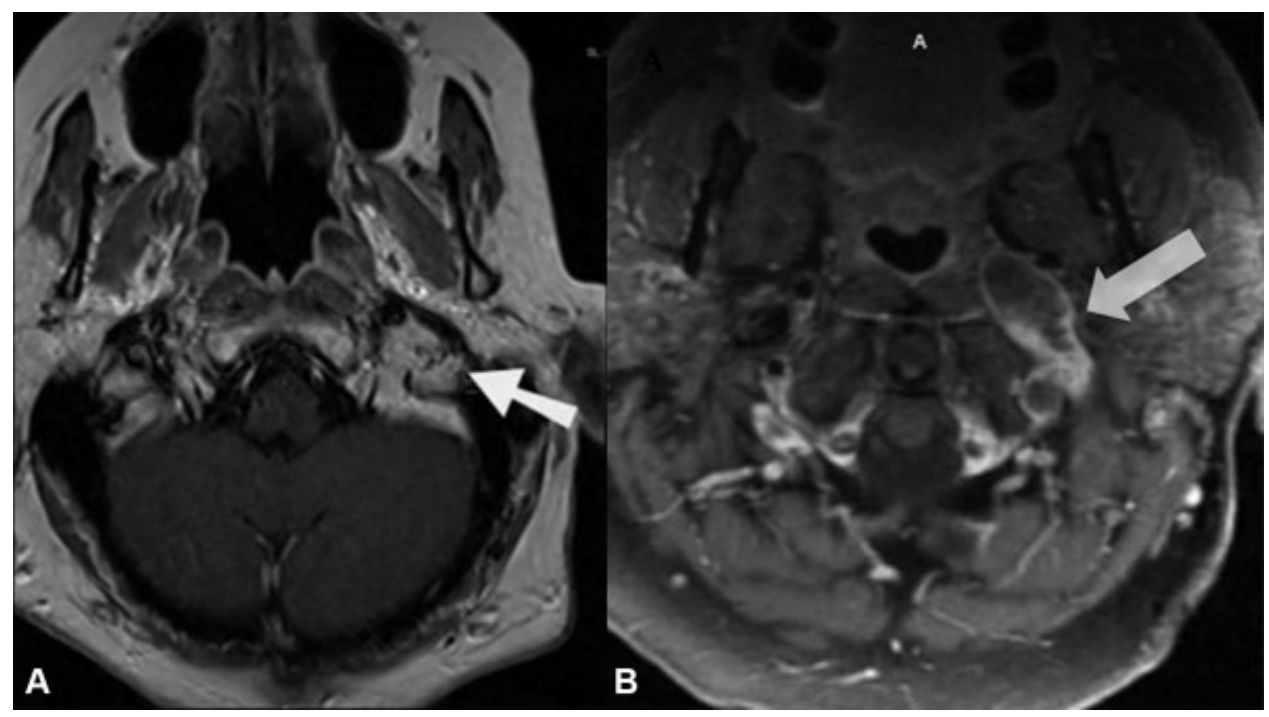

Fig. 7 (A) T1 gadolinium-enhanced magnetic resonance imaging (MRI) of a left glomus jugulare tumor. Surgical resection required detaching the digastric muscle and the rectus capitis lateralis to allow for a posterolateral exposure. (B) T1 gadolinium-enhanced MRI of a left accessory nerve schwannoma. Surgery involved reflecting the styloid and digastric muscles and removing the styloid process, to obtain an anterolateral angle of attack. Complete surgical resection was achieved in both cases. (Images courtesy of the Semmes-Murphey Clinic, Memphis, Tennessee, United States.)

jugular bulb. Liu et al reported a combined transmastoid transcondylar transtubercular high cervical approach to achieve a wide multidirectional exposure. ${ }^{12}$ This approach is designed to maximize access laterally, superiorly (infralabyrinthine), and inferiorly (trans-jugular tubercle) to the jugular foramen with added suboccipital and retrosigmoid extensions if needed.

Even though the terminology of surgical approaches to the jugular foramen is variable, and sometimes confusing, the anatomy is consistent. Understanding the anatomical relationships simplifies the involved surgical steps and allows for a focused strategy. The lateral postauricular distal cervical approach is versatile and permits different adaptations for individual cases. Preoperative imaging should be closely examined to plan surgery. Key factors include displacement of the internal carotid artery, involvement of the jugular vein, presence of intracranial disease, extension into the occipitocervical joint, location of the vertebral artery, and involvement of the hypoglossal canal.

We suggest a simplified model to deconstruct the surgical anatomy and lateral approach to the jugular foramen into geometrical windows and landmarks, based on previous descriptions, our laboratory observations, and the senior author's clinical experience. However, operating on jugular foramen pathology remains complex and necessitates dedicated skull base training. The present dissections were performed on injected cadaveric specimens, and extrapolating the actual measurements to live conditions may not be accurate

\section{Conclusion}

To simplify the anatomy and surgical approaches to the jugular foramen, we propose an anatomical model that collectively includes contiguous surgical triangles leading to the region. These triangles permit a deconstruction of individual steps and helps in choosing a strategy adapted to each individual case. The postauricular lateral distal cervical approach is flexible and can offer a $280^{\circ}$ exposure around the jugular foramen.

\section{Conflict of Interest}

No financial or material support was accepted as part of this study. None of the authors have any financial relationships to disclose.

\section{Acknowledgments}

The authors also wish to thank Andrew J. Gienapp for copy editing, preparation of the manuscript and figures for publishing, and publication assistance. The authors also thank Sebastian Cornell, Ruth Mangram, Robin Bozarth, and Tiffany Reed for their tremendous support at the cadaver laboratory.

\section{References}

1 Al-Mefty O, Teixeira A. Complex tumors of the glomus jugulare: criteria, treatment, and outcome. J Neurosurg 2002;97(06): 1356-1366

2 Sekhar LN, Schramm VL Jr, Jones NF. Subtemporal-preauricular infratemporal fossa approach to large lateral and posterior cranial base neoplasms. J Neurosurg 1987;67(04):488-499

3 Fortes FS, da Silva ES, Sennes LU. Mandibular subluxation for distal cervical exposure of the internal carotid artery. Laryngoscope 2007;117(05):890-893

4 Pellegrini RV, Manzetti GW, DiMarco RF, Bekoe S, Arena SA, Marrangoni AG. The direct surgical management of lesions of the high internal carotid artery. J Cardiovasc Surg (Torino) 1984; 25(01):29-35

5 Kumins NH, Tober JC, Larsen PE, Smead WL. Vertical ramus osteotomy allows exposure of the distal internal carotid artery to the base of the skull. Ann Vasc Surg 2001;15(01):25-31 
6 Fisch U. Infratemporal fossa approach to tumours of the temporal bone and base of the skull. J Laryngol Otol 1978;92(11):949-967

7 Gardner G, Cocke EW Jr, Robertson JT, Trumbull ML, Palmer RE. Combined approach surgery for removal of glomus jugulare tumors. Laryngoscope 1977;87(5 Pt 1):665-688

8 Rhoton AL Jr. Jugular foramen. Neurosurgery 2000;47(3, Suppl): S267-S285

9 George B, Tran PB. Surgical resection of jugulare foramen tumors by juxtacondylar approach without facial nerve transposition. Acta Neurochir (Wien) 2000;142(06):613-620

10 George B, Lot G, Tran Ba Huy P. The juxtacondylar approach to the jugular foramen (without petrous bone drilling). Surg Neurol 1995;44(03):279-284

11 Matsushima T, Natori Y, Katsuta T, Ikezaki K, Fukui M, Rhoton AL. Microsurgical anatomy for lateral approaches to the foramen magnum with special reference to transcondylar fossa (supracondylar transjugular tubercle) approach. Skull Base Surg 1998;8 (03):119-125

12 Liu JK, Sameshima T, Gottfried ON, Couldwell WT, Fukushima T. The combined transmastoid retro- and infralabyrinthine transjugular transcondylar transtubercular high cervical approach for resection of glomus jugulare tumors. Neurosurgery 2006;59(01, Suppl 1):ONS115-ONS125, discussion ONS115-ONS125

13 Matsushima K, Kohno M, Komune N, Miki K, Matsushima T, Rhoton ALJr. Suprajugular extension of the retrosigmoid approach: microsurgical anatomy. J Neurosurg 2014;121(02):397-407

14 Wen HT, Rhoton ALJr, Katsuta T, de Oliveira E. Microsurgical anatomy of the transcondylar, supracondylar, and paracondylar extensions of the far-lateral approach. J Neurosurg 1997;87(04):555-585

15 Spektor S, Anderson GJ, McMenomey SO, Horgan MA, Kellogg JX, Delashaw JB Jr. Quantitative description of the far-lateral transcondylar transtubercular approach to the foramen magnum and clivus. J Neurosurg 2000;92(05):824-831

16 Salas E, Sekhar LN, Ziyal IM, Caputy AJ, Wright DC. Variations of the extreme-lateral craniocervical approach: anatomical study and clinical analysis of 69 patients. J Neurosurg 1999;90(2, Suppl):206-219

17 Dallan I, Bignami M, Battaglia P, Castelnuovo P, Tschabitscher M. Fully endoscopic transnasal approach to the jugular foramen: anatomic study and clinical considerations. Neurosurgery 2010; 67(3, Suppl Operative):ons1-ons7, discussion ons7-ons8

18 Komune N, Matsushima K, Matsushima T, Komune S, Rhoton AL Jr. Surgical approaches to jugular foramen schwannomas: an anatomic study. Head Neck 2016;38(Suppl 1):E1041-E1053

19 Michael LM, Hamm W, Robertson JH. Surgical Management of Intracranial Glomus Tumors. In: Badie B, ed. Neurosurgical Operative Atlas: Neuro-Oncology. 2nd edition. New York: Thieme; 2006:251-259

20 Neurosurgery AANS. The Postauricular Transtemporal Approach to the Jugular Foramen. [Video]. 2017https://www.youtube.com/ watch? $\mathrm{v}=\mathrm{ijR} 1 \mathrm{wR} 4 \mathrm{xvrI}>$. Accessed June 6, 2018

21 Nelson RA. Temporal Bone Surgical Dissection Manual. Los Angeles, CA: House Ear Institute; 1983

22 Baron EM, Tunstall R. Back. In: Standring S, ed. Gray's Anatomy: The Anatomical Basis of Clinical Practice. 41st edition. New York: Elsevier; 2016:710-750

23 Heros RC. Lateral suboccipital approach for vertebral and vertebrobasilar artery lesions. J Neurosurg 1986;64(04): 559-562

24 Cohen MA, Evins AI, Lapadula G, Arko L, Stieg PE, Bernardo A. The rectus capitis lateralis and the condylar triangle: important landmarks in posterior and lateral approaches to the jugular foramen. J Neurosurg 2017;127(06):1398-1406

25 Wanibuchi M, Friedman AH, Fukushima T. Photo Atlas of Skull Base Dissection: Techniques and Operative Approaches. New York, NY: Thieme; 2008

26 Rouvière H. Anatomie humaine: descriptive, topographique et fonctionnelle [Human Anatomy: Descriptive, Topographic and Functional] Vol 1: Tête et cou [Head and Neck]. 11th edition. Paris: Masson; 1981

27 Beretta F, Hemida SA, Andaluz N, Zuccarello M, Keller JT. Exposure of the cervical internal carotid artery: surgical steps to the cranial base and morphometric study. Neurosurgery 2006;59(01, Suppl 1):ONS25-ONS34, discussion ONS25-ONS34

28 Izci Y, Moftakhar R, Pyle M, Başkaya MK. Retromandibular fossa approach to the high cervical internal carotid artery: an anatomic study. Neurosurgery 2008;62(05, Suppl 2):ONS363-ONS369, discussion 369-370 